\title{
CAMINHO(S) DA PESQUISA: DA PRÁXIS DA CATALOGAÇÃO AO FAZER-SE PELA MIGRAÇÃO
}

\author{
Marciana Santiago de Oliveira
}

Mestranda pelo Programa de Pós-Graduação em História da Faculdade de Ciências Humanas da Universidade Federal da Grande Dourados (UFGD). E-mail: marcianasantiago@hotmail.com. Bolsista Capes - Coordenação de Aperfeiçoamento de Pessoal de Nível Superior.

\section{RESUMO}

Pretende-se apontar o(s) caminho(s) percorrido(s) para a delimitação temática, temporal e espacial da pesquisa acadêmica, ou seja, o diálogo entre a Arquivologia e a Teoria da História no trabalho de catalogação, descrição e análise das fontes do acervo documental do Instituto Administrativo Jesus Bom Pastor (IAJES). Desta forma, se faz necessário discutirmos algumas questões, como: O que é um documento histórico? Existe diferença entre arquivo e acervo? Como analisar as fontes? Como organizá-las? Como classificá-las? Como disponibilizá-las para consulta? O trabalho adotado refere-se ao ofício do arquivista ou do historiador? Prática deste trabalho permitiu apreender na série do Boletim das migrações Vai Vem, das décadas de 1981 a 2010, uma possibilidade de pesquisa histórica.

Palavras-chave: Arquivologia; História; Catalogação; Migração.

\section{INTRODUÇÃO.}

O presente texto abordará as perspectivas e os desafios da prática do trabalho de análise, descrição e catalogação das fontes do IAJES $^{1}$, bem como a discussão teórica sobre preservação e construção de ferramentas de pesquisa - atividades privilegiadas no ofício do arquivista -, a partir da delimitação temática, temporal e espacial - elementos essenciais no ofício do historiador -, o que permitiu pensar na delimitação da pesquisa histórica.

No início do trabalho de catalogação, no Núcleo de Documentação ${ }^{2}$, os manuscritos amarelados e cheirando a mofo, fugiam do nosso olhar como concepção de fontes em potencial (OLIVEIRA, 2012, p. 7). Porém, com o decorrer do trabalho, entendemos que as fontes são ferramenta primordial do ofício do historiador, no seu sentido mais amplo de possibilidades de fontes históricas. E que, portanto, trata-se de um processo, uma construção do olhar do graduando/pesquisador, já que a própria definição de documento histórico é de difícil acordo entre os historiadores.

\footnotetext{
${ }^{1}$ Desenvolvido pelo grupo PET-História “Conexões de Saberes”, no Núcleo de Documentação Histórica “Honório de Souza Carneiro" (NDH), do Curso de História da Universidade Federal do Mato Grosso do Sul, Campus de Três Lagoas (UFMS/CPTL).

${ }^{2}$ Cabe apontar que os centros universitários nascem com finalidade primordial de "dar ênfase à memória regional. Sua dinâmica de trabalho envolve a reunião, preservação, e a organização de arquivos, bem como de coleções e outros conjuntos documentais. Oportunizando assim, o acesso às fontes, em sua maioria fontes primárias, à comunidade acadêmica e local”. (CAMARGO, 1999, p. 50-59).
} 


\section{A prática da Arquivologia e a Teoria da História}

Nos fins do século XIX, para os historiadores da escola positivista, documentos históricos eram somente os escritos, especialmente os oficiais: "O melhor historiador seria aquele capaz de manter-se o mais próximo possível dos textos, despojando-se de 'ideias preconceituosas'. Em resumo o documento falaria por si só" (VIEIRA, 1999, p. 14).

Já na década de 1920 amplia-se a noção de documento por meio de outra concepção da História, a Escola dos Annales, principalmente com Marc Bloch e Lucien Febvre. Nesta concepção as fontes não falam por si próprias. É preciso lançar as perguntas ao documento, e essas podem ou não serem respondidas, ou talvez a partir delas surjam novos problemas, e que caberá ao historiador investigá-los. Como já apontado por Marc Bloch (2001, p. 8): “Mesmo o mais claro e complacente dos documentos não fala senão quando se sabe interrogá-lo. É a pergunta que fazemos que condiciona a análise e, no limite, eleva ou diminui a importância de um texto retirado de um momento afastado".

Amplia-se a noção de documento, consequentemente as abordagens ao mesmo. Uma das abordagens possíveis é o entendimento que o acontecer histórico se faz a partir das ações voluntárias ou involuntárias do homem, assim sendo, o documento histórico é tudo aquilo que um apontado momento determinar que um vestígio se faça documento, seja pela sua narrativa ou pelos seus sujeitos históricos que o compõe: "Para o historiador, o documento atinge valor pela teia social que o envolve e pelo que revela de mais amplo de uma época e de uma sociedade" (KARNAL e TATSCH, 2009, p. 21).

A compreensão de documento foi crucial para navegarmos em tamanha preciosidade que estava em nossas mãos, esperando vir à tona histórias de lutas, alegrias, sofrimentos, trajetórias de vida de homens e mulheres; experiências humanas que permitem (re)descobrir a própria dimensão do homem com o meio e seu tempo. Talvez a partir daí, a prática desenvolvida pelos graduandos/pesquisadores no universo arquivístico começara a fazer sentido, e consequentemente, tornou-se mais complexo, porquanto não era simplesmente separar papéis de um dado acervo ${ }^{3}$, tratavam-se de fontes em potencial, vestígios históricos na sua mais bela compreensão da e para História.

Inúmeras possibilidades no caminho da pesquisa foram apresentadas cotidianamente por meio do fazer-se da pesquisa histórica - delimitação temática, temporal e espacial, juntamente

\footnotetext{
${ }^{3}$ A autora Marilena Paes (2009, p. 23-24) nos ajuda a compreender a diferença entre arquivo e acervo. Este último é entendido como "um conjunto de documentos de um arquivo", já que arquivo é "designação genérica de um conjunto de documentos produzidos e recebidos por uma pessoa física ou jurídica, pública ou privada, caracterizado pela natureza orgânica de sua acumulação e conservado por essas pessoas ou por seus sucessores, para fins de prova ou informação".
} 
com o trabalho de catalogação do acervo do IAJES. Fontes riquíssimas, especialmente sobre a História Social dos movimentos populares de Andradina, noroeste do estado de São Paulo, Três Lagoas, Mato Grosso do Sul, e região, dentro do recorte temporal de 1962 a 1990 considerando os anos de atuação deste Instituto.

Devido à importância deste acervo, neste momento dirigiremos nosso olhar para a história do IAJES segundo a dissertação de mestrado de Mariana Esteves de Oliveira (2006), O grito abençoado da periferia: Trajetórias e Contradições do lajes e dos Movimentos Populares de Andradina dos anos 1980, para compreendermos um pouco da dinâmica deste Instituto, já que os trabalhos de catalogação e de delimitação do tema de pesquisa exigiram apreender esta dinâmica.

Conforme Oliveira (2006), o IAJES era uma organização dirigida por padres, como o padre João Carlos Oliveri e outras pessoas inspiradas na Teologia da Libertação. O Instituto ficou conhecido por seu caráter religioso, sobretudo partidário de esquerda, tendo em seus referenciais a inspiração nas ideias marxistas. Suas ações eram de cunho assistencial e político, pautadas em "conseguir um envolvimento sempre maior da população da periferia no processo de seu desenvolvimento comunitário, através de intervenções que visem como meta prioritária a educação popular libertadora" ${ }^{4}$. Dentro do universo destas ações estavam os seguintes movimentos: negros, indígenas, mulheres, sociedade de amigos de bairro ( $S A B$ 's), Comunidade Eclesiais de Base (CEB's), pela reforma agrária, pela saúde e pelo fortalecimento do Partido dos Trabalhadores (PT), entre outros.

O Instituto IAJES desde seus primeiros passos preocupou-se com sua documentação, tendo em vista a importância do processo de elaboração e produção, entre a prática de preservar e organizar os documentos internos produzidos pelo mesmo e os demais documentos externos recebidos de algumas regiões do Brasil e do mundo, como: correspondências, jornais, boletins, fotos, vídeos, revistas, convites dentre outros, resultando em vasta massa documental, no total de 190 caixas-arquivos ${ }^{5}$.

A preocupação de preservação da memória salientada pelos Movimentos Sociais demonstra que os militantes do IAJES lutavam também “(...) no campo político intelectual da produção do saber histórico, que não são apenas atores da cena política mas, ainda, autores que a escrevem, ou que, pelo menos, apontam as diretrizes para essa escrita, a influenciam" (OLIVEIRA, 2007, p. 6).

\footnotetext{
${ }^{4}$ Caderno do IAJES, 1979, p. 03. Apud Oliveira (2006, p.109).

${ }^{5}$ São aproximadamente 100 metros lineares de documentos, com a seguinte diversidade de suporte: manuscritos, livros editados, documentos datilografados, digitados, impressos, mimeografados, jornais, revistas, correspondências, fotografias, slides, filmes e fitas de áudio. Maiores informações no "Guia do acervo" (OLIVEIRA, 2010, p. 43-47).
} 
Em 1990 o Instituto se encontrava em declínio em vista das contradições que lhe eram concernentes, dentro do campo religioso e político no contexto do abalo sofrido pelos movimentos populares da chamada Nova Esquerda. No ano de 2006 o Instituto sofreu uma penalidade judicial, o que levou a leilão o prédio onde se armazenava o acervo documental. Nesse mesmo ano, com o contato e a ajuda da professora Mariana Esteves de Oliveira, o Núcleo de Documentação Histórica "Honório de Souza Carneiro" pleiteou e logrou a guarda desse material. Professores e alunos da graduação passaram a trabalhar coletivamente na limpeza e separação da documentação no próprio galpão do IAJES (OLIVEIRA, 2010, p. 44).

Após esta primária e necessária separação dos documentos fez-se a divisão das fontes por assunto, que no caso é o mais aconselhado quando se tem um acervo grande de documentos, como assinala Marilene Leite Paes (2006, p. 77).

Em um segundo momento, a organização por assunto ou temática tem sido do geral para o particular, todavia a divisão dos documentos por subgrupos, que exige um processo de descrição, caracterização de conjuntos documentais muito particulares - especificamente da estrutura do documento, tem exigido dedicação maior, principalmente para entender a lógica da produção documental e organização do acervo do IAJES. Para esta descrição procurou-se identificar o ano do documento e os assuntos que se entrelaçam para que possam ser agrupados, tentando formar, assim, as séries ${ }^{6}$.

Por vezes, este trabalho em arquivos é considerado pelo viés de sua praticidade, como uma técnica de organização documental. Porém, não é um exercício mecânico, pois se faz necessário estar atento às particularidades da instituição produtora dos documentos, compreender sua organização e funcionamento, entre outros, como salientado por Paes (2006, p. 18).

Sendo assim, o elo entre a História e a Arquivologia se dá a partir desse momento, em que os graduandos/pesquisadores começam não só a ter um contato com as fontes, mas a trabalhar na catalogação das mesmas. Trabalho que às vezes se vê na dicotomia entre o oficio do historiador e do arquivista: onde o arquivista vê as fontes pela sua tipologia, o historiador tem um olhar para a fonte como indício/vestígio histórico (OLIVEIRA, 2012, p. 8).

A complexidade deste universo enriquece ainda mais a formação deste profissional, que se vê na necessidade de dialogar entre as duas áreas do conhecimento, a Arquivologia e a História, tendo como meio privilegiado o documento e a práxis do ensino e da pesquisa dentro do Núcleo de Documentação.

\footnotetext{
6 "Preso numa série, o documento deixa de existir sozinho, para só adquirir sentido mediante relação com a série que o precede ou segue" (KARNAL \& TATSCH, 2009, p. 244). 
Foi neste processo que vislumbramos ${ }^{7}$ na série do Boletim das migrações Vai Vem, da década de 1980, que compõe o acervo do IAJES no grupo "Movimento Migratório", uma possibilidade de pesquisa histórica.

\section{Boletim das migrações Vai Vem: Estudos de cartas}

O Boletim Vai Vem era editado pelo Centro de Estudos Migratórios, São Paulo (Missionário de São Carlos) e Centro Pastoral dos Migrantes, S. Bernardo do Campo (Diocese de Santo André), e enviado para diversas regiões do Brasil, entre elas a cidade de Andradina, noroeste do estado de São Paulo, mais especificamente para o Instituto Administrativo Jesus Bom Pastor que coordenava diversas ações junto aos migrantes na região.

O Centro de Estudo Migratório (CEM), em parceria com o Centro Pastoral de Migrantes (CPM), passou a publicar, em junho de 1981, o Boletim vai vem, primeiramente trimestral e depois bimestral, até o ano de 2010, quando se tem o último número publicado. Para esta pesquisa utilizaremos as séries catalogadas no Núcleo de Documentação Histórica “Honório de Souza Carneiro" - NDH que totalizam quatorze exemplares da década de 1980.

Cabe destacar os objetivos e as ações dos Centros que compunham o editorial do Boletim, para entender ou ao menos iniciar a compreensão dos motivos que norteavam a publicação deste periódico.

O Centro de Estudos Migratórios nasceu em 1969 e se integrou à Federação dos Centros de Estudos Migratórios João Batista Scalabrini, que congrega os demais Centros de Estudos da Congregação, presentes nas seguintes cidades: São Paulo, Nova York, Paris, Roma, Buenos Aires, Manila e Basileia. O Boletim tem como um de seus objetivos fornecer informações qualificadas e assessorar os agentes que atuam no atendimento à população migrante, a Pastoral do Migrante e os Movimentos Sociais. Procura, ainda, dialogar com pesquisadores e formadores de opinião, no sentido de aumentar o intercâmbio entre a academia e os agentes que atuam junto aos migrantes, incidindo assim em favor de uma maior sensibilização e melhoria das condições de vida dos migrantes. Já o Centro Pastoral de Migrantes - CPM tem como objetivo acolher as pessoas que migram, atendendo as suas necessidades imediatas, desenvolvendo atividades de convivência e socioeducativas por meio de assistência jurídica, religiosa, social e psicológica ${ }^{8}$.

O Centro de Estudos Migratório e Centro Pastoral dos Migrantes organizavam o periódico com o intuito de promover as lutas dos migrantes por meio das próprias experiências migratórias.

\footnotetext{
7 "O bom historiador se parece com o ogro da lenda. Onde fareja carne humana, sabe que ali está sua caça" (BLOCH, 2001, p. 20).

${ }^{8}$ Informações sobre CEM e CPM foram retiradas do site do Centro Migratório de São Paulo. Link: http://www.missaonspaz.org/\#!cem 
Deste modo, as cartas que eram enviadas e publicadas pelo editorial se tornam extremamente importantes para entendermos a organização deste Boletim e, sobretudo, o universo migratório.

Podemos salientar que o editorial do Boletim tinha como objetivo ser um instrumento do próprio migrante para consolidar e fomentar suas lutas por meio da organização social dos movimentos populares migratórios. As notícias encaminhadas ao Boletim eram selecionadas para publicação de acordo com as experiências dos migrantes apresentadas em entrevistas e/ou nas cartas enviadas ao editorial ou escritas nos encontros promovidos aos migrantes:

Durante o mês de agosto, o centro de estudos Migratório realizou um encontro de migrantes que partilharam suas experiências, suas angústias, suas esperanças e formas de luta. (...) Parte do encontro foi reservada para que os próprios migrantes escrevessem cartas aos seus parentes e amigos que estivessem para sair de suas terras e vir para a cidade. (Boletim das migrações Vai Vem, ano 3, no 11, mês: dezembro, ano: 1983, p. 4-5).

O trabalho de catalogação de fontes foi crucial para a delimitação temporal e espacial do tema de pesquisa. Ou melhor, o caminho da pesquisa se inicia com o trabalho de catalogação das fontes à compreensão do universo migratório no Brasil na década de 1980, por meio do Boletim das migrações Vai Vem e pelas cartas de homens e mulheres migrantes que eram enviadas para o editorial do periódico e publicadas na íntegra.

\section{CONCLUSÕES}

O presente estudo buscou traçar algumas possibilidades do fazer da pesquisa histórica que se desenvolveu pela prática inicial do trabalho de descrição, análise e catalogação das fontes do Instituto Administrativo Jesus Bom Pastor - IAJES - desenvolvido pelo grupo PET-História "Conexões de Saberes", no Núcleo de Documentação Histórica "Honório de Souza Carneiro" (NDH) do curso de História da Universidade Federal do Mato Grosso do Sul, Campus de Três Lagoas.

Por meio desta pesquisa, fruto do trabalho inicial de catalogação de fontes, pode-se evidenciar a riqueza do acervo do IAJES que esta esperando novos problemas e novas abordagens, para fazer-se conhecer e a práxis do ensino e da pesquisa dentro do Núcleo de Documentação, bem como seus desafios e perspectivas para realização do trabalho do graduando/pesquisador.

\section{REFERÊNCIAS}

BLOCH, Marc. Apologia da História, ou, o ofício do historiador. Rio de Janeiro: Jorge Zahar, 2001. 
CAMARGO, Célia Reis. Os Centros de Documentação das Universidades: tendências e perspectivas. IN: Arquivos, patrimônio e memória: Trajetórias e perspectivas. Zélia Lopes SILVA (org.). São Paulo: Editora UNESP: FAPESP, 1999. - (Seminário \& Debates).

KARNAL, Leandro; TATSCH, Flávia G. Documento e História - a memória evanescente. In: PINSKY, Carla B; LUCA, Tãnia Regina de (Orgs.). O historiador e suas Fontes. São Paulo: Contexto, 2009.

OLIVEIRA, Mariana Esteves de. O grito abençoado da periferia: Trajetórias e contradições do IAJES e dos movimentos populares na Andradina dos anos 1980. Maringá 2006. Dissertação de Mestrado em História - Departamento de História, Universidade Estadual de Maringá.

. Lutar, Anotar E Lembrar - Uma reflexão sobre a produção da memória dos movimentos populares e suas possibilidades de pesquisa. Associação Nacional de História - ANPUH. XXIV Simpósio Nacional de História - 2007.

OLIVEIRA, Vitor Wagner Neto de Oliveira (coordenador). Núcleo de Documentação histórico "Honório de Souza Carneiro": Guia do acervo. Três Lagoas, Mato Grosso do Sul: Gráfica Dom Bosco, 2010.

- Centros De Documentação Nas Universidades: Preservação E Pesquisa. IN: Zueleide Casagrande de Paula; Lúcia Glicério Mendonça; Jorge Luis Romanello (Orgs.). Polifonia do Patrimônio. Londrina, EDUEL, 2012.

PAES, Marilena Leite. Arquivo: teoria e prática - 6 reimp. - Rio de Janeiro: Editora FGV, 2006. 